\title{
User friendly electronic modules for AIMS
}

\author{
K. Keerthi and P. Amala Kumari
}

Received: 25.01.2018; Revised: 06.05.2018; Accepted: 23.05.2018

See end of the paper for authors' affiliations

\section{K. Keerthi}

Department of Home Science

Extension and Communication

Management, College of Home

Science, Professor Jayashankar

Telanagna State Agricultural

University, Saifabad, Hyderabad

(Telangana) India

Email : keerthikobaku@yahoo.

com
ABSTRACT : Digitization in education industry has totally changed the learning and also the teaching process to a very great extent. For the first time with an innovative idea the College of Home Science, Professor Jayashankar Telanagna State Agricultural university with enthusiastically started a digital application called Academic Information Management System (AIMS) which is Student Academic Performance Repository (SAPR). The frequency of usage of internet marketing is also fast spreading. Moreover, access to digital devices to seek information is also towering. This sort of information seeking behavior may not be an extraordinary feature of the stakeholders of College of Home Science. Hence electronic module was chosen as the curtain raiser method to create awareness and motivation to login to the web portal SAPR. The six variables viz., self-efficacy, perceived satisfaction, interactivity in portal, perceived usefulness, perceived ease of use and behavioral intention that influence the use of multimedia based instructions in learning management systems. Before execution of the checklist, the reliability was computed through Cronbach's alpha, which is a measure of internal consistency to conclude how closely a set of items are related. It is considered to be a measure of scale reliability. The $\alpha$ of the checklist, developed to measure the user friendliness of electronic modules was found as 0.89 , which was an indication of good intercorrelationsamong items. The indicator self-efficacy was the stakeholders' judgment of their capabilities to organize and execute action required according to the Electronic Module (EM) for attaining desired performance, while perceived satisfaction was the level of comfort during practicing the activities prescribed in EM. Interactivity was the interaction between the learners and the system's sources, the communication between the instructor and the learners, as well as the collaboration among the learners supported by the system under use and perceived usefulness was intention to use e-learning systems. The results were indicative of user friendliness of EM. Comparatively the indicators perceived satisfaction and perceived usefulness scored high than the other four indicators. Also the indicators perceived ease of use and behavioral intention scored less compared to other four. It is suggested that an increase in the multimedia features and interactivity of the system could lead to higher perceived usefulness and ease of use among stakeholders, and both factors add to stakeholders' perceived satisfaction which in turn increases their engagement.

KEY WORDS: Electronic module, Student repository, Digitization, User friendliness, Satisfaction

- HOW TO CITE THIS PAPER : Keerthi, K. and Kumari, P. Amala (2018). User friendly electronic modules for AIMS. Asian J. Home Sci., 13 (1) : 405-408, DOI: 10.15740/HAS/AJHS/13.1/405-408. Copyright@ 2018: Hind Agri-Horticultural Society. 